\title{
Green nanofiber mat from HLM-PVA-Pectin (Hibiscus leaves mucilage-polyvinyl alcohol-pectin) polymeric blend using electrospinning technique as a novel material in wound-healing process
}

\author{
Srijita Sen ${ }^{1} \cdot$ Trishna Bal $^{1} \cdot$ Aditya Dev Rajora $^{1}$
}

Received: 21 October 2021 / Accepted: 27 November 2021 / Published online: 14 January 2022

(c) King Abdulaziz City for Science and Technology 2021

\begin{abstract}
The present work is focused on fabrication of novel nanofiber (NF) mat as wound-healing scaffold using blends of novel combination of Hibiscus rosa-sinensis leaves mucilage (HLM)-Polyvinyl alcohol (PVA)-Pectin, which was never reported previously. Different ratios of the polymeric blends were electrospun by setting different parameters to achieve best possible electrospun nanofiber mat which was later crosslinked by glutaraldehyde vapor. The optimized formulation of nanofiber mat was characterized using Fourier-transform infrared spectroscopy (FTIR), X-ray diffraction (XRD), and thermogravimetric analysis (TGA). The crosslinked sample was evaluated for its efficacy in wound healing using Swiss albino mice model, where rapid healing of excised wound was observed with faster epithelization in test mice group than control mice within a period of 8 days. The hemolysis test with optimized crosslinked nanofiber mat $\mathrm{CrNF}(\mathrm{S} 7-\mathrm{CL})$ indicated it to be hemo-compatible. There were no traces of optimized $\mathrm{CrNF}$ (S7-CL) when placed under the skin hypodermis in test mice groups revealing its biodegradable nature. The degradation pattern of $\mathrm{CrNF}(\mathrm{S} 7-\mathrm{CL})$ in soil reflects its eco-friendly behavior. Thus, the prepared nanofiber grade $\mathrm{CrNF}(\mathrm{S} 7-\mathrm{CL})$ can be considered as a novel material for faster wound healing and can also be explored for other biomedical applications.
\end{abstract}

Keywords Hibiscus mucilage · Pectin · Polyvinyl alcohol · Nanofiber mat · Electrospinning · Glutaraldehyde crosslinking · Wound healing

\section{Introduction}

Nanofibers (NF) are one-dimensional nanomaterial (Kenry and Lim 2017) like nanorods, nanotubes, having approximate diameter of 50-500 nm (tunable to 5-10 nm or less; known as nanofibril), favoring in nanoworld due to its uniqueness and adaptable nature, even in the COVID-19 pandemic, nanofiber-based face mask (Essa et al. 2021) has become a weapon with extraordinary qualities of breathable filter, multiple sterilizability. Unique morphological characteristics including tunable porousness, high surface area-to-volume ratio, flexibility with sufficient tensile strength have encouraged researchers to utilize its uniqueness in fullest extent in

Trishna Bal

trishna.bal@gmail.com

1 Department of Pharmaceutical Sciences \& Technology, Birla Institute of Technology, Mesra, Ranchi 835215, Jharkhand, India different areas of regenerative medicine, tissue engineering, controlled drug delivery vehicles, vaccine designing and in other biomedical disciplines. NF-based material can meet almost all the features of ideal dressing material which is superior than most of the available topical wound care systems like films, foams, hydrocolloids, etc. Sufficient oxygen supply, recapitulation of extracellular matrix of the skin, easy incorporation of bioactive molecules, regulation of skin cell behavior are the extraordinary qualities of NF scaffolds. In the current study, Hibiscus leaves mucilage (HLM) has been explored to prepare a novel wound-healing polymeric scaffold along with two other different polymers Pectin and Polyvinyl alcohol (PVA). Previously, HLM has been studied to develop different edible sustained release dosage forms in the recent years. Also, HLM has been reported to exert antimicrobial action against both Gram-positive and Gram-negative bacteria (Rm and Nair 2018). The significant amount of uronic acids (Glucuronic acids, Galacturonic acids) present in the HLM may be the important contributors to control oxidative stress related to wound. HLM is also 
able to provide additional optimal skin moisturizing effect which prevent the wounds from drying out, to become itchy. (Kassakul et al. 2014) On the other hand, pectin, a watersoluble hetero-polysaccharide with broad-spectrum antibacterial activity. The antimicrobial intensity, however, varies depending upon the source from which it is extracted. Polar carboxylic group in pectin chain helps to absorb fluids from wound and can retain water of multiple times of their weight. Pectin has been shown to be effective in wound management when prepared as hydrogel-based or hydrocolloid, self-adhesive wound dressings (Mishra et al. 2011)(Rezvanian et al. 2017). Therefore, combination of Hibiscus mucilage and pectin in the nanofiber scaffold will play an important role to treat infective wounds. PVA is water-soluble synthetic polymer, generally recognized as safe (GRAS) has been widely investigated as excipient and used in many commercial formulations. Addition of PVA with natural polymers helps to strengthen the mechanical quality of the nanofiber scaffold and also imparts polarity to the films and at the same time enhances the thermal stability of the fibers. The present study is mainly focused on the fabrication of green nanofiber mat via single-needle electrospinning technique utilizing Hibiscus leaves mucilage (HLM) blended with pectin and polyvinyl alcohol (PVA). Moreover, this combination of HLM-Pectin-PVA has never tried before for preparation of nanofibers as well as never applied as polymeric scaffold to the best of our knowledge. To obtain a continuous stable jet during the electrospinning, polymer blend must have sufficient viscoelastic properties and thus concentration and proportion of the three components have been optimized to get required spinnability, stretchability and production of uniform nanofibers. Prepared scaffolds have been subjected to glutaraldehyde- $\mathrm{HCl}$ vapor crosslinking method for enhancing the tensile strength of nanofiber mats (NFMs). To see the impact of crosslinking on the nanofiber mat, these were evaluated for change in nanofiber morphology, thermal degradation pattern, tensile strength with that of pure pectin, HLM and PVA. The final aim of the research is the woundhealing effect of the prepared nanofiber scaffold which was studied on excise wound model using Swiss albino mice.

\section{Materials and methodology}

\section{Extraction of mucilage}

Fresh leaves of Hibiscus rosa-sinensis were collected from BIT Mesra campus (Ranchi, Jharkhand) in the month of March-April. The extraction of mucilage is pictorially shown in Fig. 1. Collected leaves were washed with water for 2-3 times to remove all the dirt, debris and foreign materials. Leaves were cut into very small pieces and placed in a beaker containing distilled water at room temperature for $12 \mathrm{~h}$ to ensure sufficient release of mucilage from leaves into the water. To separate the mucilage, the content was filtered through muslin cloth and the process was repeated 2 times to extract remaining mucilage from the residue of leaves as much as possible. To the extract, acetone was added in

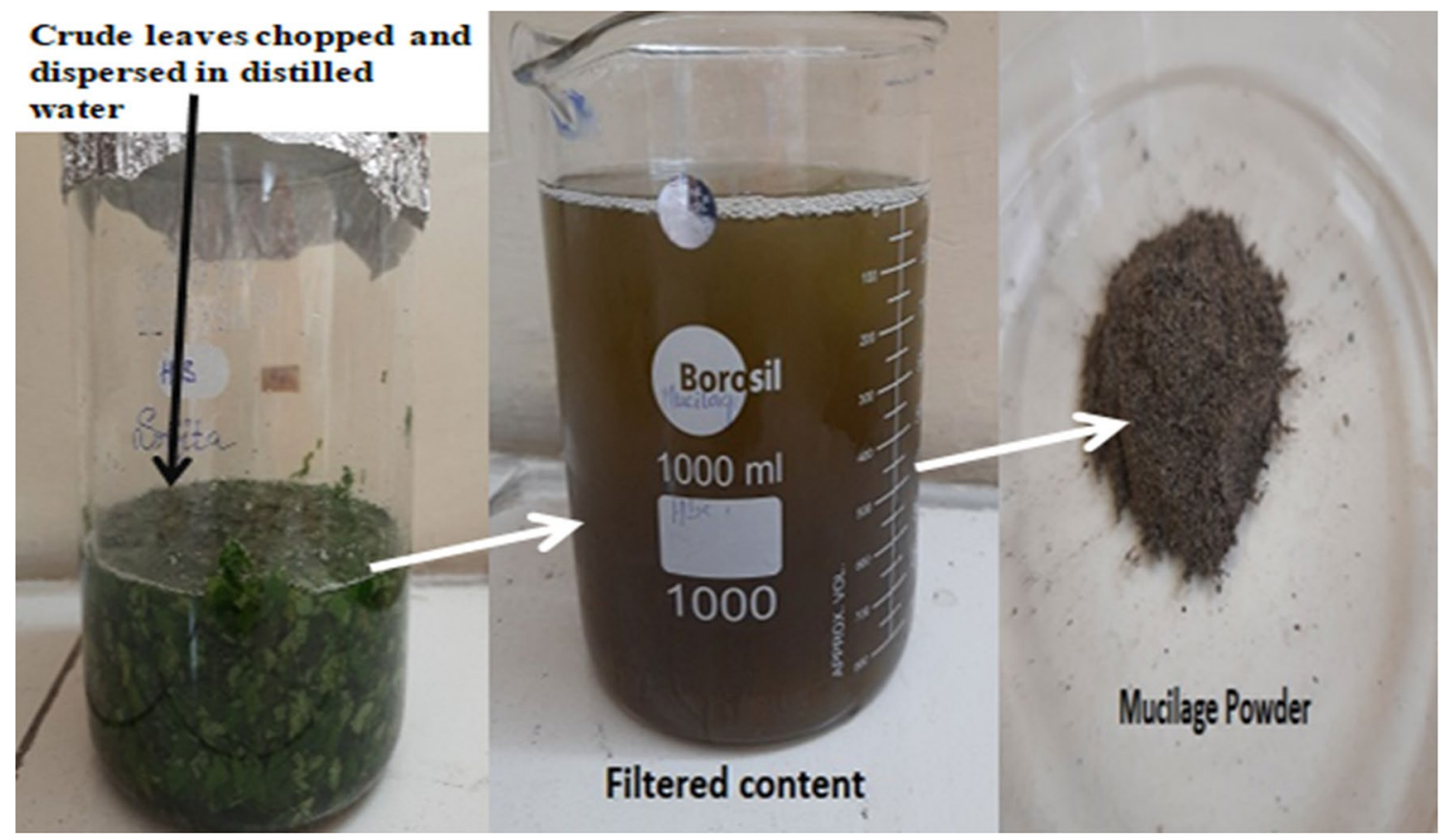

Fig. 1 Extraction process of HLM (Hibiscus leaves mucilage) 
sufficient volume for mucilage precipitation to occur. The precipitated mucilage was washed carefully with acetone and collected via filtration. Then it was kept in the hot air oven below $50{ }^{\circ} \mathrm{C}$. The dried mass was ground to fine powder and stored in air-tight container in a desiccator (Ahad et al. 2011).

\section{Preparation of polymeric blends}

Solutions of the all polymers, PVA (Thermo Fisher Scientific India Pvt. Ltd.), Pectin (HiMedia Laboratories Pvt. Ltd.) as well as pure mucilage (HLM) were prepared separately. For all cases, requisite amount of polymers was weighed as per the need of mother polymer solution concentration $(1 \% \mathrm{w} / \mathrm{v}$ mucilage, $2 \%, 5 \% \mathrm{w} / \mathrm{v}$ pectin, $10 \% \mathrm{w} / \mathrm{v}$ PVA). The pre-weighed polymers were added in the double distilled water slowly with continuous stirring until homogeneous consistency was obtained. In case of PVA, the water was heated to $65^{\circ} \mathrm{C}$ to facilitate solubilization. To obtain a clear PVA solution, it was left for overnight continuous stirring using a magnetic stirrer. Afterward, these polymeric solutions were taken in volume ratio and stirred till a uniformly miscible blend was formed. The blends were later subjected to electrospinning to obtain the desired nanofibers a shown in Table 1.

\section{Electrospinning of polymeric blends}

ESPIN-NANO, Electrospinning apparatus at Department of Bioengineering, Birla Institute of Technology, Mesra, Ranchi, as shown in Fig. 2, has been set up with a static collector plate covered with aluminum foil and injector plastic syringe fitted to a needle of diameter $0.566 \mathrm{~mm}$ loaded with polymer blend sample (volume of approximately $5 \mathrm{ml}$ ). The tip of the needle

Table 1 Optimization of nanofibers mat

\begin{tabular}{|c|c|c|c|c|c|c|c|c|}
\hline Sample & $\begin{array}{l}\text { Concen- } \\
\text { tration of } \\
\text { Pectin }(\% \mathrm{w} / \mathrm{v})\end{array}$ & $\begin{array}{l}\text { Mucilage-Pectin- } \\
\text { PVA (volume } \\
\text { ratio) }\end{array}$ & $\begin{array}{l}\text { Amount } \\
\text { of PVA } \\
(\%)\end{array}$ & $\begin{array}{l}\text { Applied } \\
\text { voltage } \\
(\mathrm{KV})\end{array}$ & $\begin{array}{l}\text { Needle to col- } \\
\text { lector distance } \\
(\mathrm{cm} .)\end{array}$ & $\begin{array}{l}\text { Flow rate } \\
(\mathrm{mL} / \mathrm{hr} .)\end{array}$ & $\begin{array}{l}\text { Forma- } \\
\text { tion of } \\
\text { fibers }\end{array}$ & Observation \\
\hline $\mathrm{S} 1$ & $2 \%$ & $1: 1: 1$ & 33.33 & 23 & 15 & 1 & No & Spray jet only \\
\hline S2 & $2 \%$ & $1: 2: 1$ & 25 & 23 & 15 & 1 & No & Spray jet only \\
\hline S3 & $2 \%$ & $2: 1: 2$ & 40 & 23 & 15 & 1 & Yes & $\begin{array}{l}\text { Spray droplets, in between } \\
\text { process }\end{array}$ \\
\hline S4 & $2 \%$ & $2: 1: 3$ & 50 & 23 & 15 & 1 & Yes & $\begin{array}{l}\text { Droplet formation, polymer } \\
\text { loss }\end{array}$ \\
\hline S5 & $2 \%$ & $1: 1: 3$ & 60 & 23 & 15 & 1 & Yes & Droplet formation \\
\hline S7 & $5 \%$ & 1:1:8 & 80 & 23 & 15 & 1 & Yes & No droplet \\
\hline
\end{tabular}
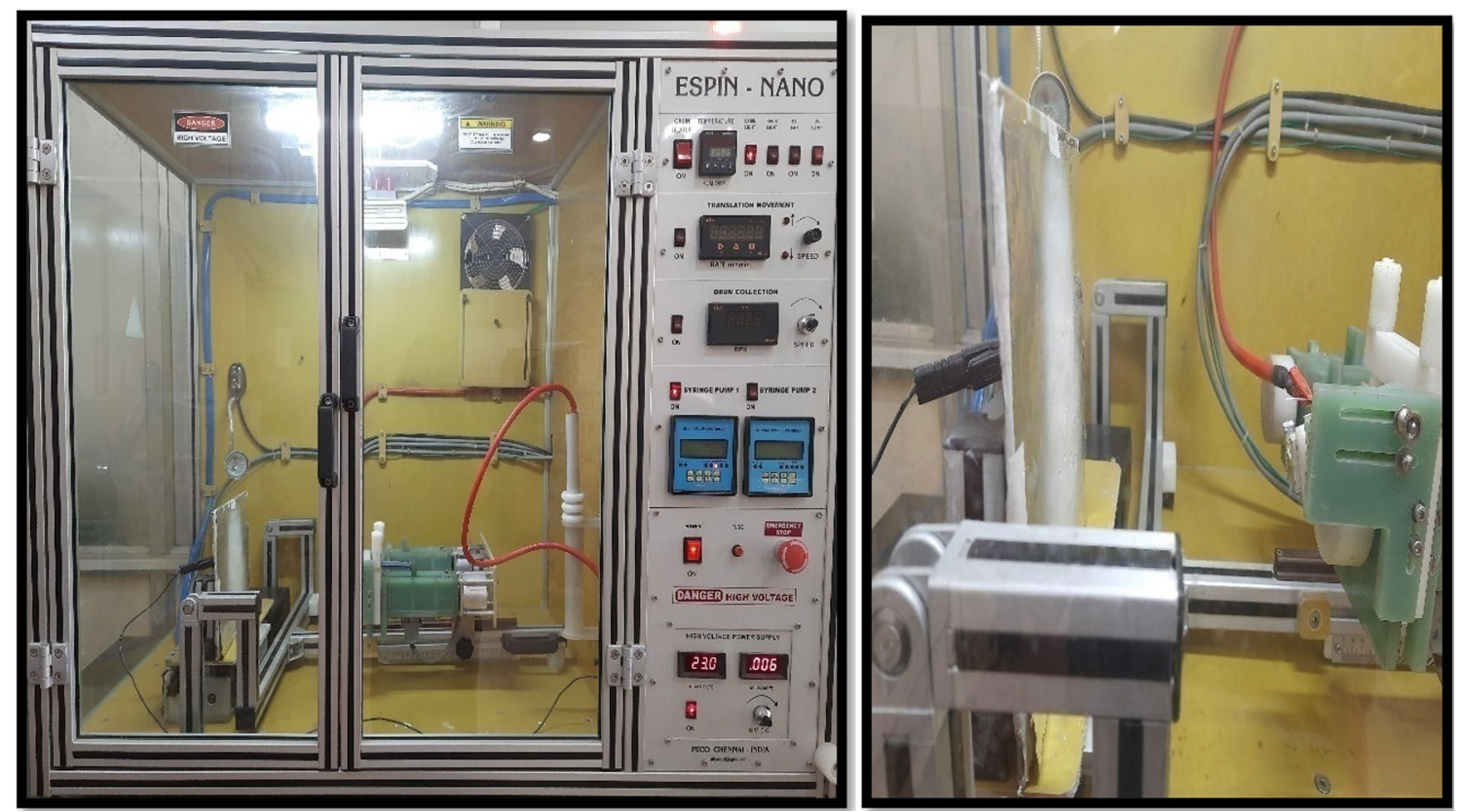

Fig. 2 Electrospinning chamber with parameter control panel (left side) and Electrospinning set up (right side) 
was always positioned aligning to the center of the collector plate. In this study, the distance between the needles from the collector plate was $15 \mathrm{~cm}$ with a flow rate of $1 \mathrm{ml} / \mathrm{min}$, was maintained throughout the experiment. After observing the effect of voltage on the fiber formation during spinning, the voltage was kept $23 \mathrm{kV}$ in all cases (Hashmi et al. 2021).

\section{Crosslinking of nanofibre mat}

Mixtures of 25\% glutaraldehyde solution (Central Drug House (P) Ltd.) and 0.5 M hydrochloric acid were taken in a beaker. Nanofiber mat, after curing time, was subjected to the vapor of the crosslinking agent inside a beaker with sufficient support and the beaker was closed tightly by aluminum foil and Petri dish to saturate the internal environment of beaker with glutaraldehyde vapor as shown in Fig. 3. The whole system was heated at about $75^{\circ} \mathrm{C}$ for periods of $3 \mathrm{~h}$ and later placed the glutaraldehyde- $\mathrm{HCl}$ vapour treated nanofiber mat inside hot air oven at $50{ }^{\circ} \mathrm{C}$ to dry and remove traces of glutaraldehyde- $\mathrm{HCl}$ vapor from the mat surface. (Dey et al. 2020).

\section{Assessment of nanofiber morphology by Field Emission Scanning Electron Microscopy (FESEM)}

For comparison of surface morphology, both the crosslinked CrNF(S7-CL) and non-crosslinked nanofiber mat were placed on a carbon tape and sputter-coated with platinum to make it conductive in nature. The samples were placed inside the specimen chamber of Sigma 300, Ziess FESEM instrument. The fibrous morphological alterations in terms of structure, swelling, etc. due to crosslinking effect were observed at random sites at different magnification from 2.5 KX to 100 KX. (Vashisth and Pruthi 2016).

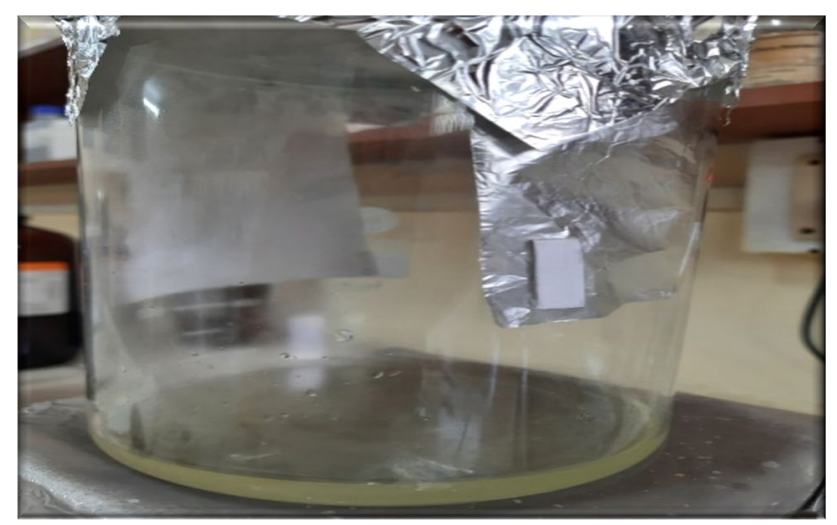

Fig. 3 Glutaraldehyde crosslinking of optimized nanofiber mat CrNF (S7-CL)

\section{Analytical characterization}

\section{X-Ray diffraction (XRD)}

Purified mucilage (HLM), pectin, PVA and CrNF(S7-CL) were subjected to XRD diffractometer, equipped with Copper K- $\alpha$ radiation. The powdered samples were packed into a hole ( $2 \mathrm{~mm}$ diameter) of a small container made up of poly(methyl methacrylate) (Perspex). (Cui et al. 2013).

\section{Fourier-Transform infrared spectroscopic analysis (FTIR)}

The infrared spectra of pure mucilage (HLM), pectin, PVA and optimized nanofiber mat $\mathrm{CrNF}(\mathrm{S} 7-\mathrm{CL})$ were recorded using FT-IR using $\mathrm{KBr}$ pellet method. Transmittance was analyzed in the mid-IR range (Dey et al. 2020).

\section{Thermogravimetric analysis (TGA)}

Thermogravimetric analyses of pure mucilage (HLM), pectin, PVA and CrNF(S7-CL) were performed in nitrogen atmosphere at $10{ }^{\circ} \mathrm{C} / \mathrm{min}$. The change of weight with temperature has been detected by DTG-60, Shimadzu, Japan. (Chatterjee and Deopura 2006).

\section{Tensile strength}

The non-crosslinked nanofiber mat and its crosslinked form [CrNF(S7-CL)] were subjected to two opposite forces that pull the mat at varying stress by the Instron tester. The point of stress at which the nanofiber mats got broken were taken into account (Abdal-Hay et al. 2016).

\section{In vivo studies}

\section{Tissue histopathological studies}

One control and one test group of Swiss albino mice each containing 6 animals were taken after approval obtained from Institutional Animal Ethics Committee [protocol approval no. 1972/ $\mathrm{PH}+\mathrm{BIT}$ 119/21/IAEC] of Birla Institute of Technology, Mesra (Ranchi, Jharkhand). The test mice were anaesthetized using diethyl ether inhalation method. Hairs from the dorsal area, just behind the neck of both the test and control mice group were removed and then a small deep incision was made. A small piece of crosslinked nanofiber mat $\mathrm{CrNF}$ (S7-CL) of $4 \mathrm{mg}$ was placed with close proximity to the tissue followed by closing the area by suturing up carefully. (Swain and Bal 2019)(Bal et al. 2020) The control group mice were left without any insertion of materials. After 5 days, the stitches were carefully opened up and the local tissues of the incised area were collected without harming the animal in anaesthetized condition and preserved in $10 \%$ formalin solution for histopathological studies. The 
collected tissues were stained with eosin dye and examined under microscope (Dey et al. 2020).

\section{Wound-healing studies on excision wound model}

Two groups (test and control) of Swiss albino mice were taken with prior approval from Institutional Animal Ethics Committee [protocol approval no. 1972/PH + BIT 119/21/IAEC] of Birla Institute of Technology, Mesra (Ranchi, Jharkhand). They were subjected to mild anesthesia by diethyl ether inhalation and small wound was created on top layer of the shaved skin of the dorsal area using forceps, pointed scissor and a surgical blade. In the test mice, $\mathrm{CrNF}$ (S7-CL) mat was placed covering the wound $\left(\left(7 \times 5 \mathrm{~mm}^{2}\right)\right.$, whereas the control mice wound $\left(7 \times 5 \mathrm{~mm}^{2}\right)$ was left untreated. The nano-fibrous matrix later got adhered to the wound. Animals were observed for total 8 days of duration and visual correlation for any signs of healing (Arunachalam and Subhashini 2011).

\section{Hemocompatibility study}

For evaluation of extent of hemo-compatibility of the test sample CrNF(S7-CL), chicken blood was collected and centrifuged at $1500 \mathrm{rpm}$ at $4^{0} \mathrm{c}$ for $20 \mathrm{~min}$. The RBCs remaining at the bottom of the centrifuge tube were washed with phosphate-buffered saline (PBS) of adjusted $\mathrm{pH}$. Washing was repeated for three times, and every time, the supernatant was discarded. RBC suspension was set up by mixing RBCs in phosphate-buffered saline (PBS). In one tube, $3 \mathrm{mg}$ of test sample was taken and gently shaken with RBC suspension which was the test sample. In another tube, RBC suspension was treated with Triton X-100 (10\% v/v) to achieve complete hemolysis which was the positive control. In the third tube, only RBC suspension treated with PBS was taken, regarded as negative control. All three tubes were incubated for $1 \mathrm{~h}$ at $37{ }^{\circ} \mathrm{C}$. After incubation, these were centrifuged at $1000 \mathrm{rpm}$ for $10 \mathrm{~min}$ and the supernatant was taken for UV spectroscopic analysis. The absorbance was taken at $540 \mathrm{~nm}$ to check the released hemoglobin as shown in Fig. 4 and was calculated using \% degree of hemolysis using Eq. 1. (Dey et al. 2020; Bal et al. 2020).

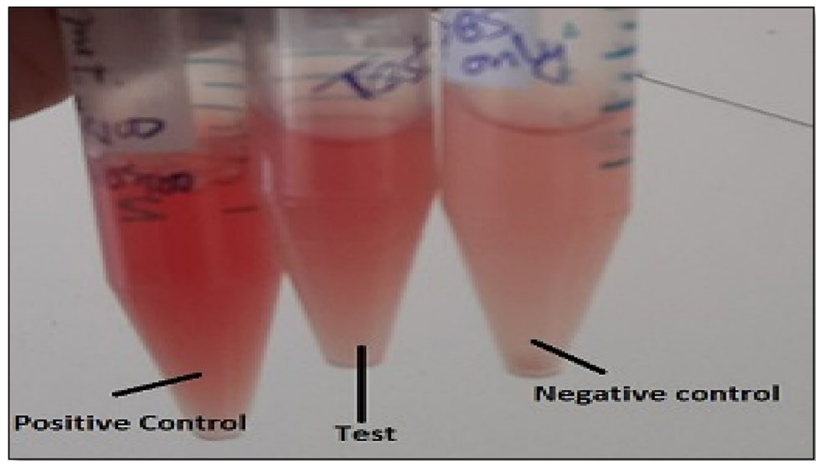

Fig. 4 Hemo-compatibility study

then weight of the system was measured regularly for 7 days. Percentage of degradation (\% weight loss) was calculated. (Altaee et al. 2016) The loss of sample weight may be influenced by several microbes present in the soil, which is strong evidence of eco-compatibility (Roy et al. 2020).

\section{Results and discussion}

\section{Optimization of nanofiber}

Polymeric blends of different volume ratios with varying amounts of PVA from $20 \% \mathrm{v} / \mathrm{v}$ to $80 \% \mathrm{v} / \mathrm{v}$ were subjected to electrospinning by ESPIN-NANO as indicated in Table 1 . There was no fiber formation when only pure mucilage (HLM) was used. There was also no fiber formation when the amount of PVA was kept at 20\%,25\% and $33 \% \mathrm{v} / \mathrm{v}$ in total polymeric blend. The reason of not forming fiber may be due to low viscosity which causes breakage of polymer jet during stretching. To minimize the use of high concentration of synthetic polymer, the concentration of pectin was raised from 2 to $5 \% \mathrm{w} / \mathrm{v}$. Minimization of droplet formation during electrospinning of samples prepared with 5\% pectin was observed, which reflects the importance of pectin concentration. Whereas, the electrospun fibers obtained with formulation S3 (2:1:2 (40\% v/v PVA) as shown in Fig. 5 and

$\%$ Degree of Hemolysis $=\frac{\text { Abs(test })- \text { Abs(negativecontrol })}{\text { Abs(Positivecontrol })-\operatorname{Abs}(\text { negativecontrol })} \mathrm{X} 100$

\section{In vitro biodegradation in soil}

Previously weighed optimized grade $\mathrm{CrNF}$ (S7-CL) was taken and placed inside soil in a clean and dry glass beaker. The initial weight of the whole system was recorded and formulation S4 [2:1:3 (50\% v/v PVA)] as shown in Fig. 5 were not of sufficient strength to peel them from the aluminum foil collector in matrix format. When PVA amount was further increased to $60 \% \mathrm{v} / \mathrm{v}(1: 1: 3)$ as in case of S5, $\mathrm{S} 6$ and to $80 \% \mathrm{v} / \mathrm{v}(1: 1: 8)$ as in case of $\mathrm{S} 7$ as shown in Table 1, electrospinning was faster with quick formation of nanofiber which had enhanced mechanical properties 
Fig. 5 Nanofiber mats prepared from different polymeric blend

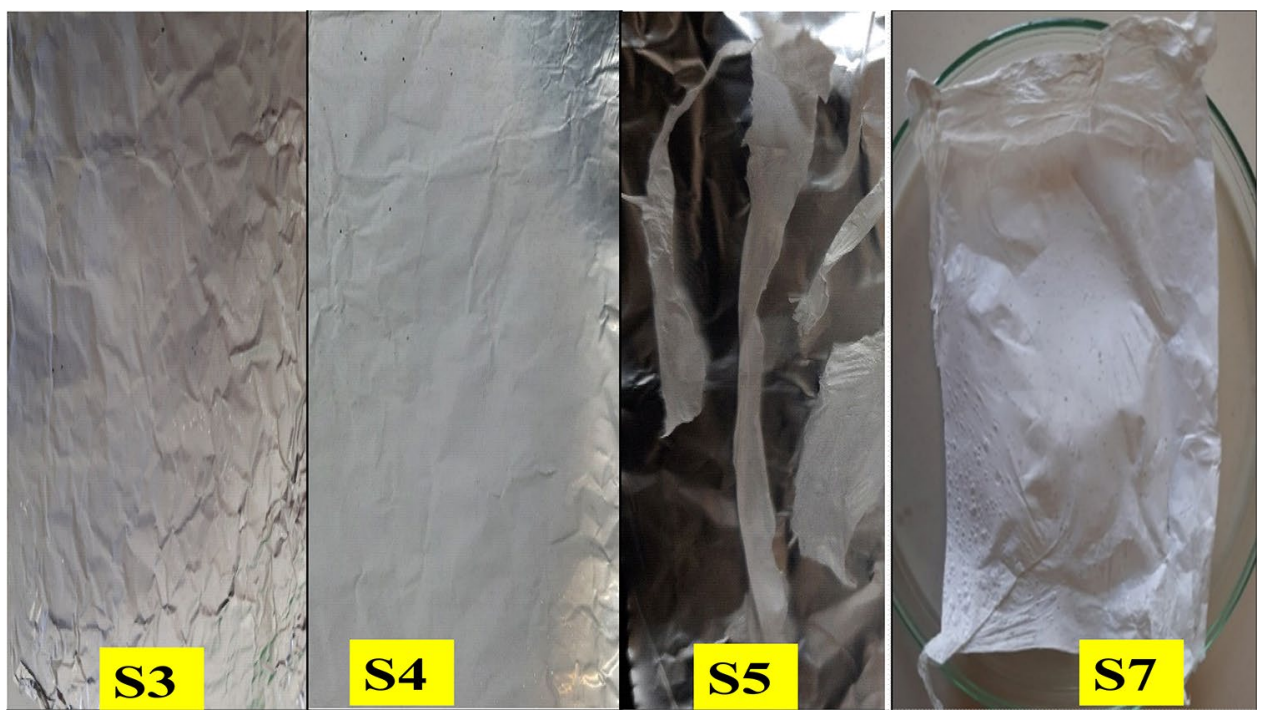

and more stretchability as shown in Fig. 5 and Fig. 6 (A). But, in case of S5, although, spinning was fast, but droplet formation was consistent, so S5 was not selected. In case of S7, when the concentration of pectin was increased to $5 \% \mathrm{w} / \mathrm{v}$ with increase in PVA content to $80 \% \mathrm{w} / \mathrm{v}$, it led to the perfect formation of nanofibers without any droplet

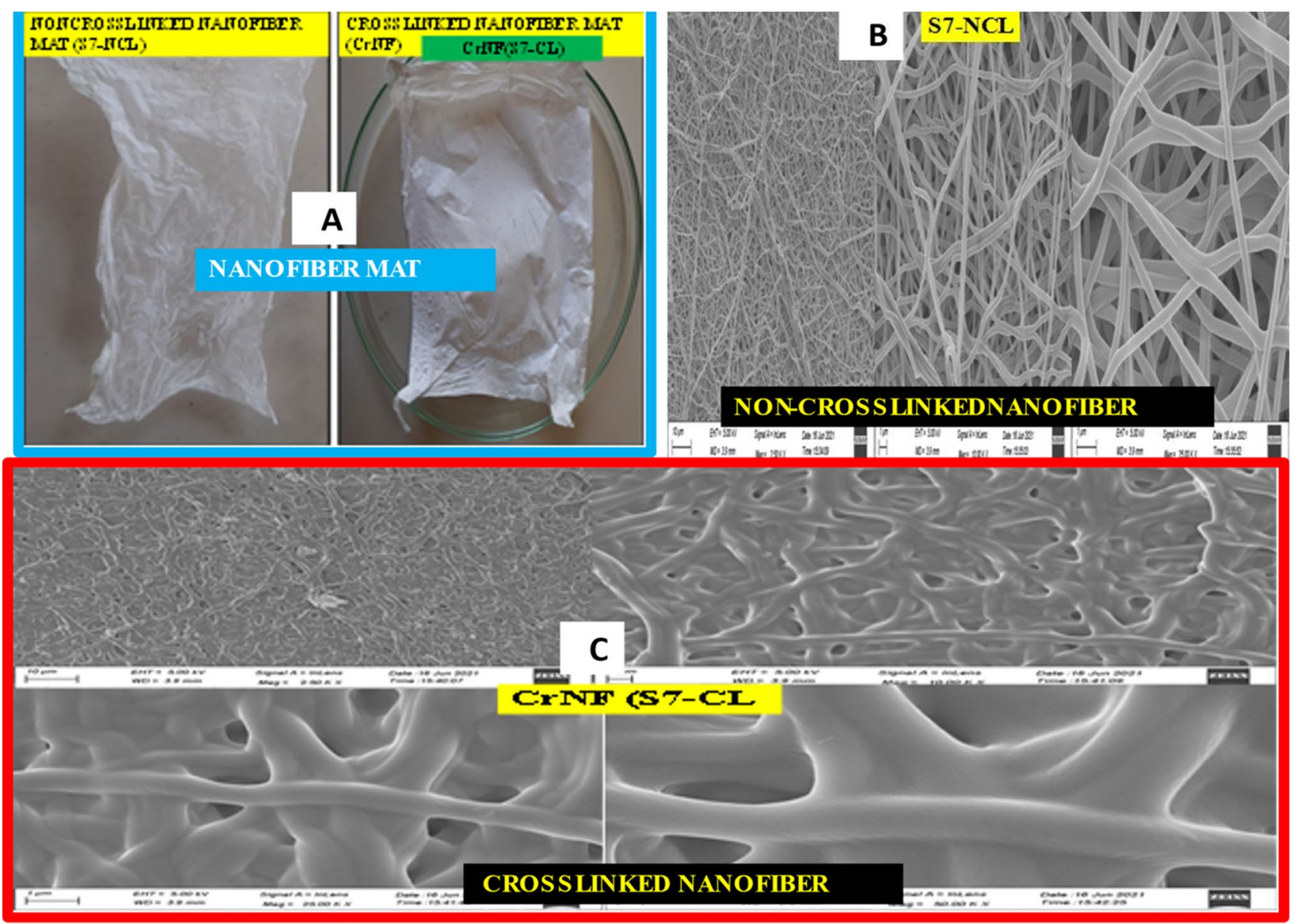

Fig. 6 Physical observation of optimized formulation S7, before crosslinking (S7-NCL) and after crosslinking (CrNF S7-CL) at different magnifications 
formation and also the process was faster, and thus formulation S7, was optimized for further characterizations.

\section{Nanofiber morphology}

The FESEM images reveal that the optimized noncrosslinked nanofibers named as S7-NCL mat as shown in Fig. 6(B), are almost homogeneous in nature with a smooth surface with no bead formation. The dimension of the optimized nanofiber mat $\mathrm{S} 7$, remained unchanged even after crosslinking with glutaraldehyde vapor which was named as $\mathrm{CrNF}(\mathrm{S} 7-\mathrm{CL})$, as shown in Fig. 6(C) although there is presence of number of many crosslinked joints which helps to increase the mechanical integrity in the nanofiber mats. It is clearly evident that in case of $\mathrm{CrNF}(\mathrm{S} 7-\mathrm{CL})$, the interfiber gap has reduced with dense mesh formation which is not there in case of non-crosslinked sample S7-NCL, (Dey et al. 2020) which makes it a perfect material for tissue scaffolding as well as other biomedical devices like in the face mask preparation.

\section{Analytical characterizations}

\section{X-Ray Diffraction Analysis}

X-ray diffraction studies have been performed by measuring the angle of diffraction (2Ө) in the range of 0 to 90 degree. Figure 7 presents the XRD pattern of pure Hibiscus leaf mucilage (HLM), pectin, PVA and crosslinked nanofiber CrNF(S7-CL). The diffractogram for PVA exhibited characteristic sharp peak at $2 \Theta=19.5^{\circ}$ and at $2 \Theta=40.25^{\circ}$ which indicated its crystalline nature. (Gonzalez et al. 2016) In case of Pectin, several sharp peaks in the diffractogram clearly depict its crystalline nature. Whereas in case of HLM, there were no sharp peaks indicating its amorphous characteristics. In case of optimized crosslinked nanofiber mat CrNF (S7-CL), consisting of HLM-pectin-PVA polymeric blend, there is almost absence of any sharp peaks, evidencing the reduction of crystallinity in nanofiber preparation.

\section{Fourier-Transform Infrared Spectroscopy}

FTIR characteristic peaks are shown in the Fig. 8 (A, B, C $\& D$ ) and in Table 2. For pure mucilage (HLM), as shown in Fig. 8(A), there is a clear indication of characteristic peaks at $805.48 \mathrm{~cm}^{-1}, 860.96 \mathrm{~cm}^{-1}$ which correspond to $\mathrm{C}-\mathrm{H}$ aromatic bond. Peaks appeared at wave number $1664.47 \mathrm{~cm}^{-1}$, $2922.72 \mathrm{~cm}^{-1}$ indicates $\mathrm{C}=\mathrm{N}$ stretching vibration and presence of C-H (alkyl) bond, respectively. (Ahad et al. 2011) In case of Fig. 8(B) for Pectin, very weak IR band appeared at $1588 \mathrm{~cm}^{-1}$ which ascribed to $\mathrm{C}=\mathrm{O}$ stretching of the pectin chain. Appearance of peak at $1743.3 \mathrm{~cm}^{-1}$ indicates stretching of ester carbonyl group. Absorption band obtained in between 1100 and $1200 \mathrm{~cm}^{-1}$ as shown in the Fig. 8(B) may be due to R-O-R bond. (Kyomugasho et al. 2015) In case of PVA as shown in Fig. 8(C), broader peak in the infrared spectrum at around $3400 \mathrm{~cm}^{-1}$ is attributed due to stretching vibration of $\mathrm{OH}$ moiety. Wave number of $1146.39 \mathrm{~cm}^{-1}$ was assigned to $\mathrm{C}-\mathrm{O}$ stretching in case of
Fig. 7 X-Ray Diffraction pattern of HLM, PVA, Pectin, and CrNF

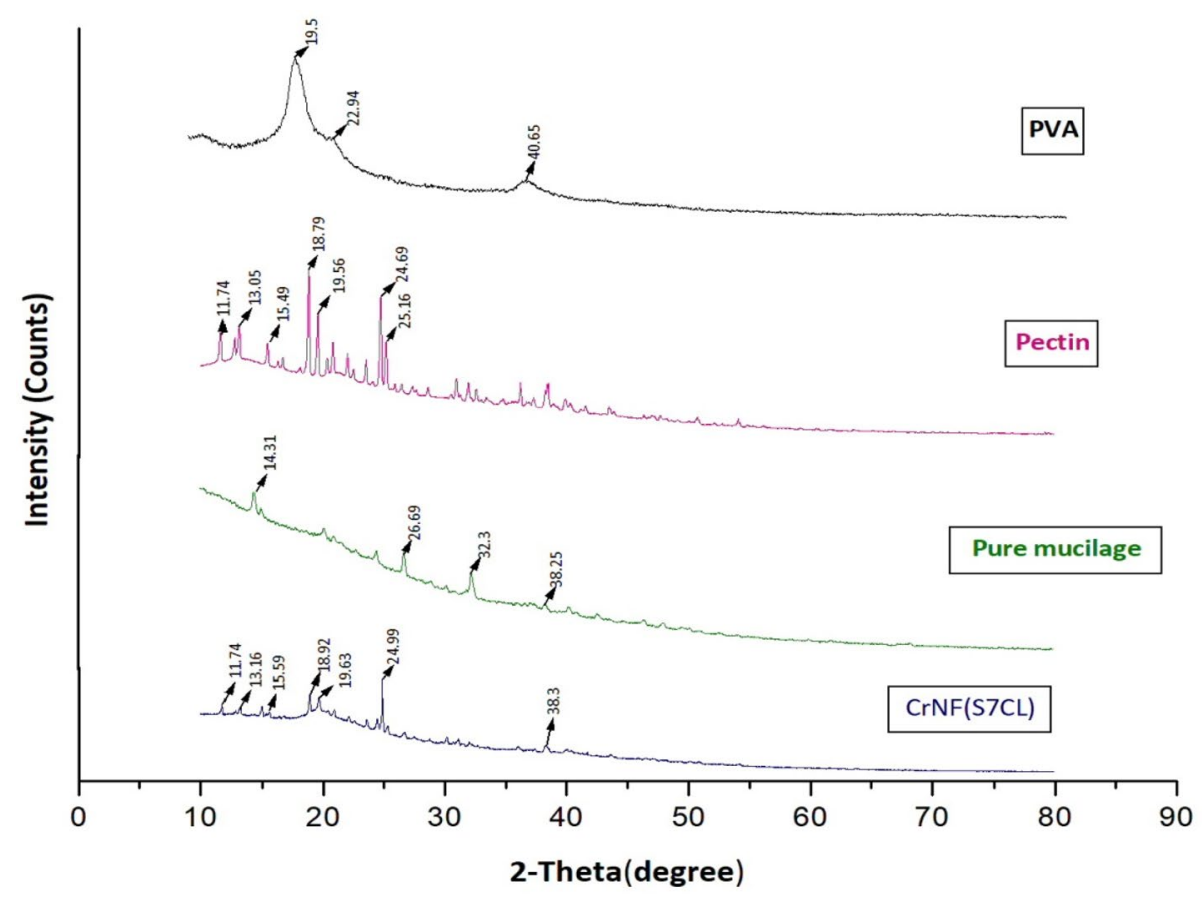

2-Theta(degree) 

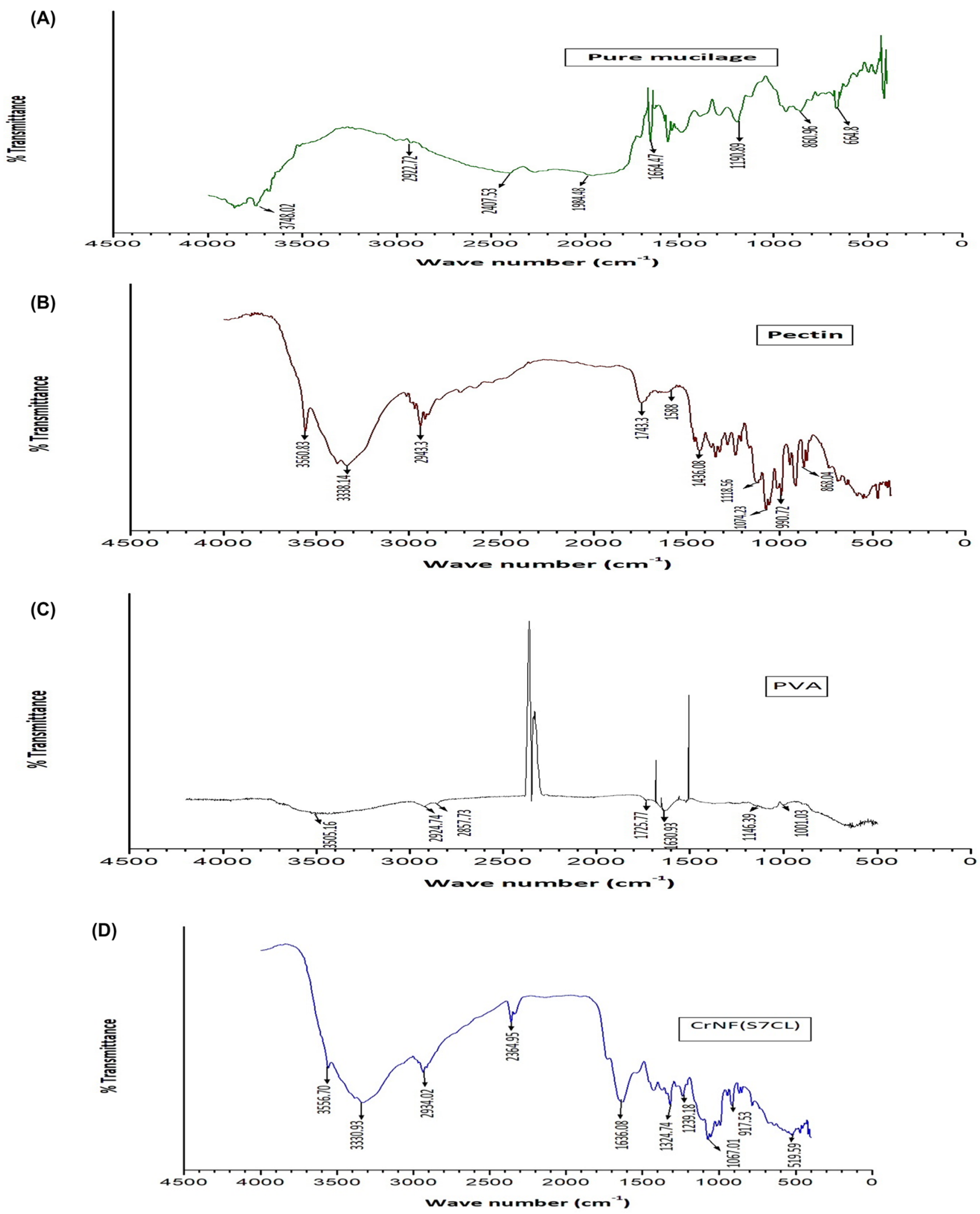

Fig. 8 FTIR spectrum of (A) Pure mucilage (HLM), (B) Pectin, (C) PVA (D) CrNF (S7-CL) 
Table 2 Interpretation of FTIR spectra

\begin{tabular}{lll}
\hline Polymer & Wave number $\left(\mathrm{cm}^{-1}\right)$ & Functional group \\
\hline Pure mucilage & $805.48,860.96$ & $\begin{array}{c}\text { Bending of } \mathrm{C}-\mathrm{H} \text { bond } \\
\text { (aromatic) } \\
\text { Stretching of } \mathrm{C}=\mathrm{N} \text { bond }\end{array}$ \\
& 1664.47 & $\mathrm{C}-\mathrm{H}$ bond (alkyl) \\
& 2922.72 & Stretching of $\mathrm{C}=\mathrm{O}$ bond \\
Pectin & 1588 & Ester group \\
& 1743.3 & Stretching of $\mathrm{C}-\mathrm{O}$ \\
PVA & 1146.39 & Stretching of C=O \\
& 1725.77 & Stretching of hydroxyl group \\
& 3505.16 & $\mathrm{C}-\mathrm{O}$ bond (ether, aromatic) \\
CrNF (S7-CL) & 1239.18 & $\mathrm{C}=\mathrm{N}$ bond, NH (primary \\
& 1636.08 & amine) \\
& 2934.02 & $-\mathrm{CH}$ group \\
& 3330.93 & Stretching of $-\mathrm{OH}$ \\
\hline
\end{tabular}

PVA. Peak corresponding to $-\mathrm{C}=\mathrm{O}$ stretching for PVA occurs at approximately $1725.77 \mathrm{~cm}^{-1}$. (Mansur et al. 2008) Characteristic peaks of the entire polymeric blend are clearly observed in the IR spectrum of $\mathrm{CrNF}(\mathrm{S} 7-\mathrm{CL})$ as shown in Fig. 8(D), and clearly reflect the presence of all three polymers in the mixture indicating polymer compatibility.

\section{Thermal studies}

Thermograms of pure mucilage (HLM), Pectin, PVA and optimized crosslinked grade $\mathrm{CrNF}$ (S7-CL) are shown in Fig. 9. The thermogram of pure mucilage HLM indicates that there are two stages of degradation, the first stage starting from 246.48 to $335.58{ }^{\circ} \mathrm{C}$ with a $\%$ weight loss of $48.557 \%$ and the second starting from 335.50 to $424.69^{\circ} \mathrm{C}$ with a weight loss of $13.099 \%$. In case of Pectin also, there are two stages of degradation with first stage starting from 200.51 to $250.43^{\circ} \mathrm{C}$ with a weight loss of $31.019 \%$ and is attributed to the loss of water and volatile substances, and in the second stage, there is $\%$ weight loss of $31.24 \%$ within the temperature range of $250.43-437.7^{\circ} \mathrm{C}$, where there is mainly the degradation of polysaccharides occurring. (Elizangela et al. 2015) In case of PVA, the degradation starts from 266.89 to $434.7{ }^{\circ} \mathrm{C}$, with a \% weight loss of $65.5 \%$, which is mainly attributed to the degradation of the $-\mathrm{OH}$ groups to polyene, and also the degradation of the $\mathrm{C}-\mathrm{C}$ backbone of the polymer as further degradation occurs from 434.7 to $481.7^{\circ} \mathrm{C}$ with a weight loss of $18.7 \%$. (Dey et al. 2020) In case of optimized crosslinked grade CrNF (S7-CL), there are two steps of degradation, starting from 210.13 to 316.38 ${ }^{0} \mathrm{C}$ with a $\%$ weight loss of $30.6 \%$ and second stage starting from 316.38 to $478.38{ }^{0} \mathrm{C}$ with a $\%$ weight loss of $18.72 \%$. Thus, in optimized crosslinked nanofiber mat $\mathrm{CrNF}(\mathrm{S} 7-\mathrm{CL})$, the overall weight loss is comparatively less than the pure mucilage (HLM), and also when compared with PVA and pectin. This is a clear indication, that after formation of the nanofibers, the stability of the pure mucilage HLM has been enhanced.

\section{Tensile strength}

The tensile strength determination is an important parameter for assessing the mechanical strength. By determining the tensile strength of the nanofiber mat, we can access the impact of crosslinking on strength of fibers and compare it with the non-crosslinked sample. In the current study, the tensile strength of pure PVA nanofiber mat, S7-NCL (noncrosslinked sample) and $\mathrm{CrNF}(\mathrm{S} 7-\mathrm{CL})$ is measured using Instron tensile Tester, and it was found that the ultimate stress required to break the nanofiber mat for crosslinked sample CrNF(S7-CL) was highest $0.590 \mathrm{MPa}$ when compared to non-crosslinked sample, which has $0.522 \mathrm{MPa}$ and pure PVA nanofiber mat having ultimate stress of $0.233 \mathrm{MPa}$ as shown in Table 3, indicating that tensile strength of crosslinked sample $\mathrm{CrNF}$ (S7-CL) is highest, thereby stating that crosslinking mechanism enhances the mechanical strength and at the same time also proves that polymeric blend enhances its mechanical strength (Dey et al. 2020).

\section{In vivo studies}

\section{Histopathological studies}

All mice were alive with normal activities throughout the implantation duration. There were no traces of nanofiber scaffolds observed after surgical opening, which show that the scaffolds are biodegradable. Moreover, it was necessary to evaluate whether the biodegraded products had any harmful effects on the local tissues, where the $\mathrm{CrNF}(\mathrm{S} 7-\mathrm{CL})$ as test sample and sterilized control ball as the control were implanted. As seen in the Fig. 10, it is clearly evident that the control local tissue although had collagen and spindleshaped fibroblast growth; but in the test tissue, there was more enhanced growth, which indicates, that CrNF(S7-CL) can be an excellent material for to be used as polymeric scaffold and other biomedical applications (Dey et al. 2020) (Garg et al. 2021).

\section{Wound-healing properties}

The progression of the wound healing was observed for 8 days. The photograph of the wound area has been preserved and visually correlated. In case of test mice, the wound area has healed faster as shown in Fig. 11 and Fig. 13, than the control mice as shown in Fig. 12. Also, as shown in Table 4 and Fig. 13, the cumulative wound contraction for test mice was $30 \mathrm{~mm}^{2}$ and in case of control

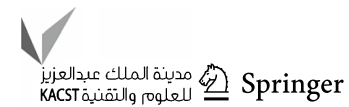




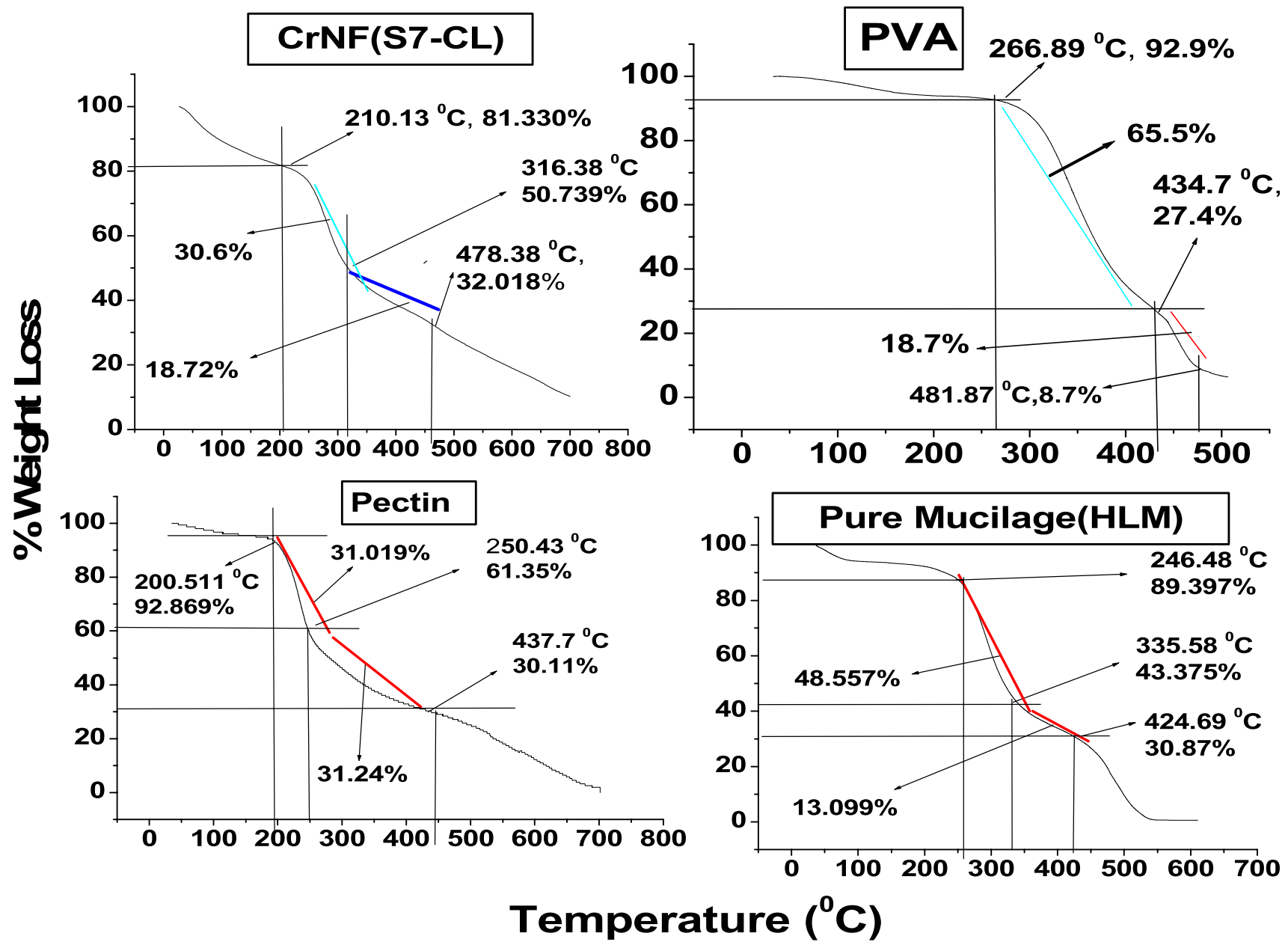

Fig. 9 Thermogravimetric curves of HLM, Pectin, PVA and CrNF (S7-CL)

Table 3 Tensile strength

\begin{tabular}{llllll}
\hline Sl.No & Sample & $\begin{array}{l}\text { Ultimate } \\
\text { Stress (MPa) }\end{array}$ & \% Ultimate Strain & Break Strain \% & Modulus (MPa) \\
\hline 1 & PVA & 0.233 & 20.813 & 20.813 & 3.589 \\
2 & S7-NCL & 0.522 & 17.5 & 26.6 & 3.88 \\
3 & CrNF(S7-CL) & 0.590 & 24.8 & 26.9 & 4.4 \\
\hline
\end{tabular}

mice is calculated to be $21 \mathrm{~mm}^{2}$, indicating that the prepared nanofiber mat heals the wound faster than the untreated surface on control mice.

Measurement of wound was taken once daily using transparent sheet. On the 8th day, the wound area in test mice is $5 \mathrm{~mm}^{2}$ which less than the wound of control mice as shown in Fig. 12.
Moreover, the percentage wound healing as calculated using Eq. 2 (Pawar et al. 2013) and graphically represented in Fig. 14, using the values as given in Table 4 is about $85.71 \%$ for test mice and $60 \%$ for control mice. Thus, it can be concluded that the prepared HLM-Pectin-PVA-based green nanofiber mat (CrNF-S7 CL) is an effective biomaterial scaffold for wound healing.

$\%$ WoundHealing $=\frac{(\text { Day1 of thewoundarea }- \text { Day8of thewoundarea })}{\text { Day1of thewoundarea }} \times 100$ 


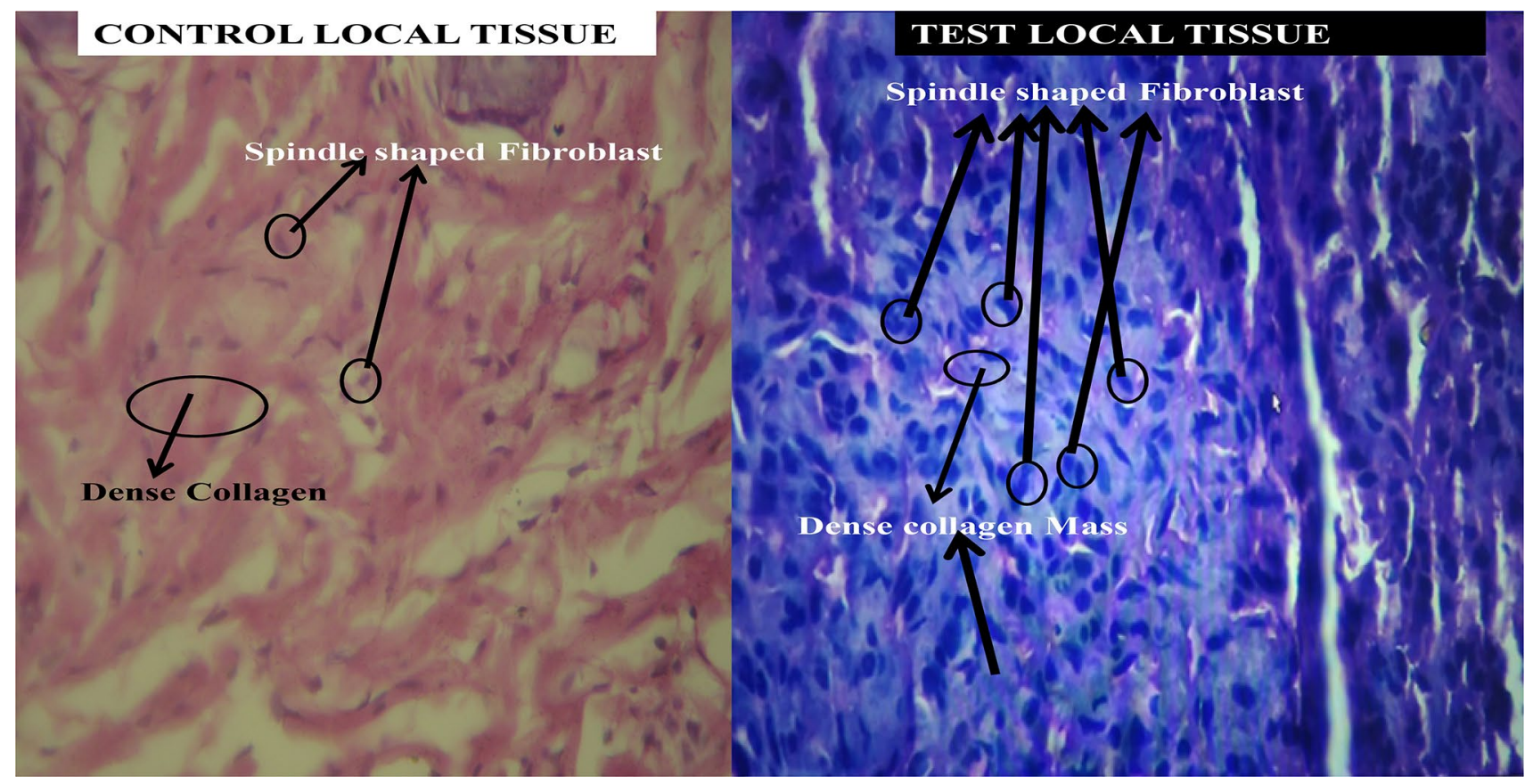

Fig. 10 Histopathology of Local Tissue of Control and Test sample [CrNF (S7-CL)] captured using Leica Microscope at 40X magnification

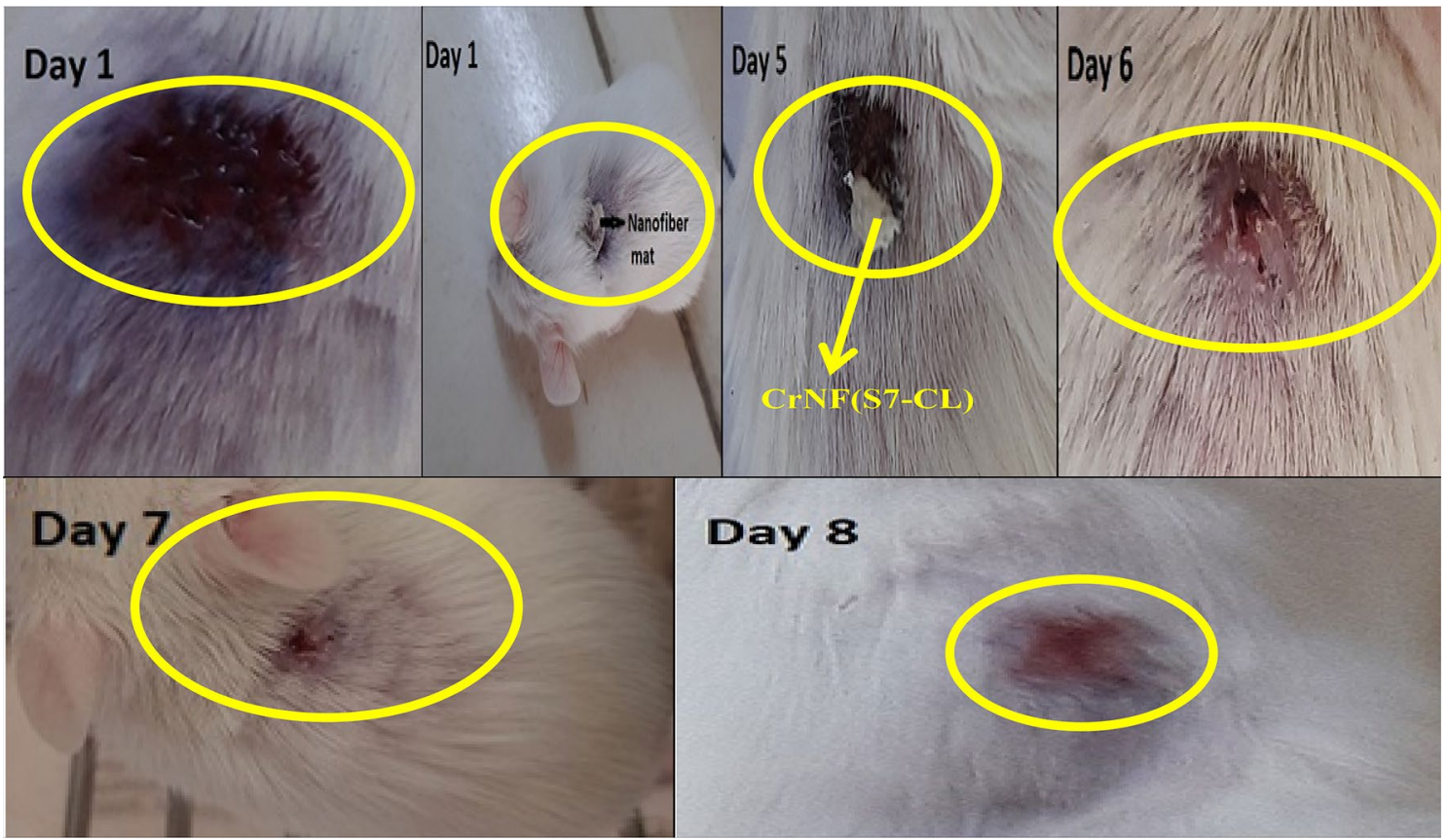

Fig. 11 Progress of wound healing in test mice

\section{Hemo-compatibility studies}

Hemo-compatibility analysis in terms of $\%$ degree of hemolysis is one of the major procedures to evaluate the biocompatibility of biomaterials. According to the result shown in Table 5, the percentage degree of hemolysis was calculated to be $1.34 \%$ which is less than $2 \%$. If degree of hemolysis is below the hemolysis index of $2 \%$, a material is considered as non-hemolytic according to the American Society for Testing and Materials (ASTM). (Roy et al.

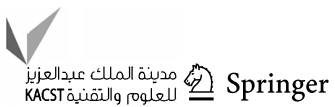




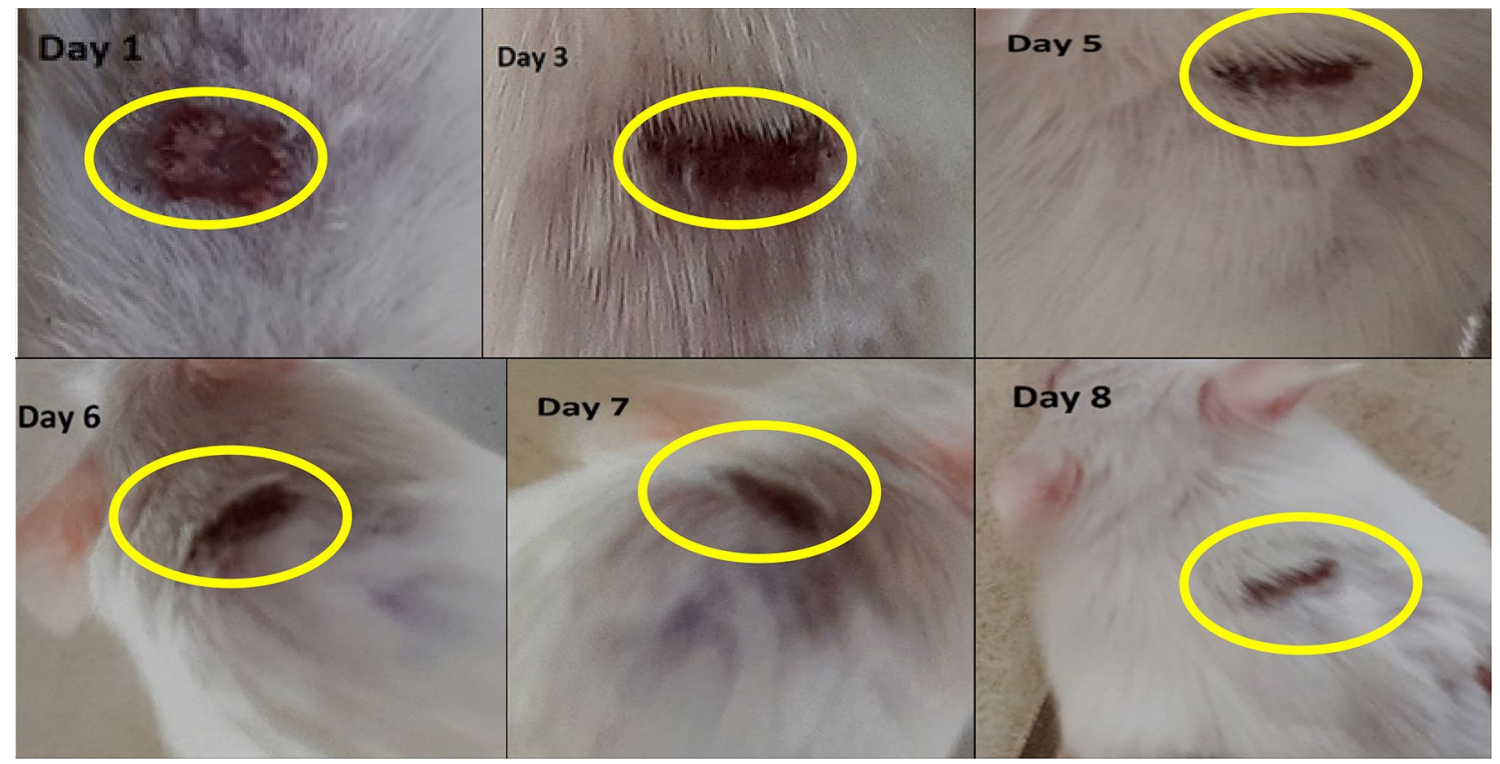

Fig. 12 Progress of wound healing in control mice

Table 4 Comparison of wound healing in Test and Control mice

\begin{tabular}{llll}
\hline Mice & Day & $\begin{array}{l}\text { Wound area } \\
\left(\mathrm{mm}^{2}\right)\end{array}$ & $\begin{array}{l}\text { Cumulative wound } \\
\text { contraction }\left(\mathrm{mm}^{2}\right)\end{array}$ \\
\hline Control & 1 st & 35 & 0 \\
& 5 th & 17.5 & 17.5 \\
& 6 th & 16 & 19 \\
& 7th & 16 & 19 \\
\multirow{4}{*}{ Test } & 8th & 14 & 21 \\
& 1 st & 35 & 0 \\
& 5 th & 16 & 19 \\
& 6 th & 13 & 22 \\
& 7th & 9 & 26 \\
& 8th & 5 & 30 \\
\hline
\end{tabular}

Test mice Control mice

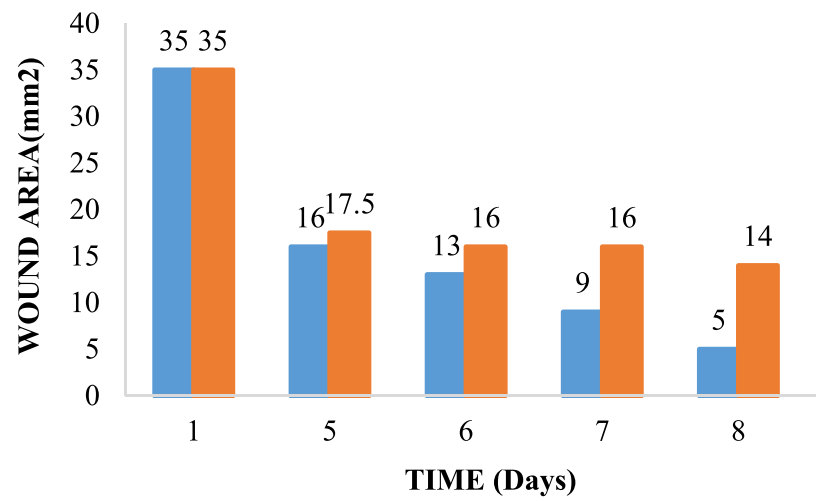

Fig. 13 Relative contraction of wound

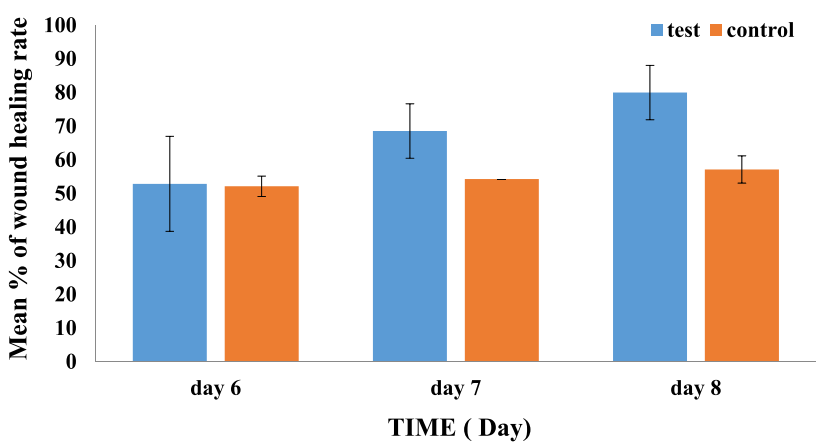

Fig. $14 \%$ Wound-healing rate (mean \pm S.D.)

Table 5 Absorbance of samples related to the degree of hemolysis

\begin{tabular}{lll}
\hline Sample & $\begin{array}{l}\text { Absorbance (at } \\
540 \mathrm{~nm})\end{array}$ & Hemolysis (\%) \\
\hline Test & 0.120 & \\
Negative control & 0.109 & $1.34 \%$ \\
Positive control & 0.928 & \\
\hline
\end{tabular}

2020) (Rai et al. 2020) Therefore, the optimized sample $\mathrm{CrNF}(\mathrm{S} 7-\mathrm{CL})$ can be concluded as safe and can be explored in biomedical and tissue engineering (Table 5).

\section{In vitro Degradation in soil}

In vitro biodegradation study in soil was done by placing the sample into the soil. Progressive loss of weight was observed for period of 7 days as shown in Table 6 and 
Table $6 \%$ Weight loss of sample by soil degradation

\begin{tabular}{llll}
\hline Day & $\begin{array}{l}\text { Total weight of the } \\
\text { system }(\mathrm{gm} .)\end{array}$ & $\begin{array}{l}\text { Change in weight } \\
(\mathrm{gm} .)\end{array}$ & $\%$ Weight loss \\
\hline $1^{\text {st }}$ & 70.002 & 0 & 0 \\
$2^{\text {nd }}$ & 70 & 0.002 & 0.0029 \\
$5^{\text {th }}$ & 69.944 & 0.056 & 0.08 \\
$6^{\text {th }}$ & 69.825 & 0.119 & 0.17 \\
$7^{\text {th }}$ & 69.185 & 0.64 & 0.916 \\
\hline
\end{tabular}

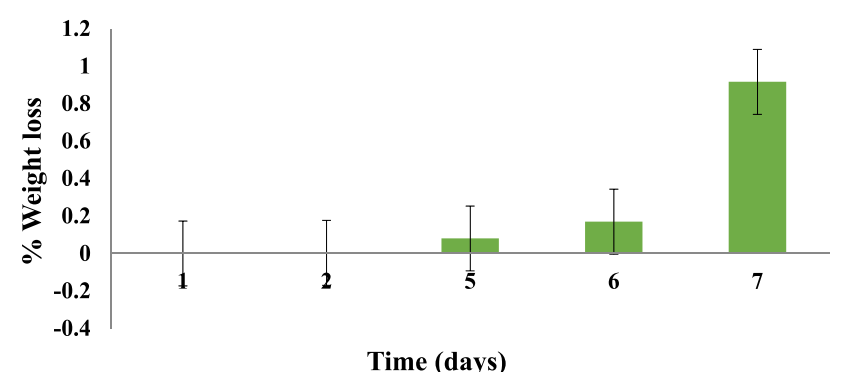

Time (days)

Fig. 15 Degradation pattern in soil

Fig. 15, which clearly indicated that the sample is environmentally friendly being biodegradable.

\section{Conclusion}

Present research mainly focused on preparing green nanofiber as polymeric scaffold from novel combination of two natural polymers and a synthetic polymer that can effectively combine their positive attributes during processing. The molecular concentration of polymers as well as volume ratio has been optimized to attain sufficient viscosity that neither obstructing the flow from the needle nor causing the droplet formation. The obtained nanofibers were subjected to chemical crosslinking by glutaraldehyde vapor, facilitating interlinking between nanofibers that can enhance the stability as well as durability. Analytical characterization has been established in the compatibility between the polymers. The research has been further emphasized on the woundhealing property of the prepared nanofiber scaffold. In vivo animal study has been confirmed the faster epithelisation and contraction of wound on application of the green nanofiber scaffold. Moreover, the nanofibers were found to be hemocompatible and underwent biodegradation that again confirm their suitability as biomaterials. Degradation behavior in the soil provides assurance of eco-friendly nature which can be further taken into account to develop degradable face masks as a future prospect. Thus, it can be concluded that the prepared nanofiber mat was effective as wound-healing material.
Acknowledgements The authors sincerely thank the Central Instrumentation facility and Department of Pharmaceutical Sciences and Technology, Birla Institute of Technology, Mesra, Ranchi-835215, for providing support even in this pandemic situation for carrying out this research successfully.

\section{Declarations}

Conflict of interest The authors declare that there is no conflict of interest.

\section{References}

Abdal-Hay A, Hussein KH, Casettari L et al (2016) Fabrication of novel high performance ductile poly(lactic acid) nanofiber scaffold coated with poly(vinyl alcohol) for tissue engineering applications. Mater Sci Eng C 60:143-150. https://doi.org/10.1016/j. msec.2015.11.024

Ahad HA, Yesupadam P, Ramyasree P et al (2011) Isolation and Physicochemical characterization of Hibiscus rosa-sinensis leaves mucilage. Int J Curr Res 3(4):210-212

Almeida EA, Facchi SP, Martins AF et al (2015) Synthesis and characterization of pectin derivative with antitumor property against Caco-2 colon cancer cells. Carbohydr Polym 115:139-145. https://doi.org/10.1016/j.carbpol.2014.08.085

Altaee N, El-Hiti GA, Fahdil A et al (2016) Biodegradation of different formulations of polyhydroxybutyrate films in soil. Springerplus. https://doi.org/10.1186/s40064-016-2480-2

Arunachalam KD, Subhashini S (2011) Preliminary phytochemical investigation and wound healing activity of Myristicaandamanica leaves in Swiss albino mice. J Med Plant Res 5(7):1095-1106. https://doi.org/10.5897/JMPR.9001039

Bal T, Yadav SK, Rai N et al (2020) Invitro evaluations of free radical assisted microwave irradiated polyacrylamide grafted cashew gum (CG) biocompatible graft copolymer (CG-g-PAM) as effective polymeric scaffold. J Drug Deliv Sci Technol 56:101572. https:// doi.org/10.1016/j.jddst.2020.101572

Chatterjee A, Deopura BL (2006) Thermal stability of polypropylene/ carbon nanofiber composite. J Appl Polym Sci 100:3574-3578. https://doi.org/10.1002/app.22864

Cui F, Li Y, Zhou S, et al (2013) A comparative in vitro evaluation of nanoparticles. 1-8. https://doi.org/10.1186/1556-276X-8-301

Dey P, Bal T, Gupta RN (2020) Fabrication and invitro evaluation of electrospun gum ghatti-polyvinyl alcohol polymeric blend green nanofibre mat (GG-PVA NFM) as a novel material for polymeric scaffolds in wound healing. Polym Test 91:106826. https://doi. org/10.1016/j.polymertesting.2020.106826

Essa W, Yasin S, Saeed I, Ali G (2021) Nanofiber-Based face masks and respirators as COVID-19 protection: a review. Membranes (basel) 11:250. https://doi.org/10.3390/membranes11040250

Garg S, Bal T, Panpalia SG et al (2021) Preparation and characterization of microwave irradiated $\mathrm{pH}$-sensitive polyacrylamide grafted flax seed mucilage graft copolymeric hydrogel (PFLSM-g-PAMcl-MBA) and its evaluation as effective polymeric scaffold. Sustain Chem Pharm 22:100479. https://doi.org/10.1016/j.scp.2021. 100479

Gonzalez JS, Martínez YN, Castro GR, Alvarez VA (2016) Preparation and characterization of polyvinyl alcohol-pectin cryogels containing enrofloxacin and keratinase as potential transdermal delivery device. Adv Mater Lett 8:640-645. https://doi.org/10. 5185/amlett.2016.6499 
Hashmi M, Ullah S, Ullah A et al (2021) Carboxymethyl cellulose $(\mathrm{Cmc})$ based electrospun composite nanofiber mats for food packaging. Polymers (basel) 13:1-12. https://doi.org/10.3390/polym 13020302

Kassakul W, Praznik W, Viernstein H et al (2014) Characterization of the mucilages extracted from hibiscus rosa-sinensis linn and hibiscus mutabilis linn and their skin moisturizing effect. Int $\mathbf{J}$ Pharm Pharm Sci 6:453-457

Kenry LCT (2017) Nanofiber technology: current status and emerging developments. Prog Polym Sci 70:1-17. https://doi.org/10.1016/j. progpolymsci.2017.03.002

Kyomugasho C, Christiaens S, Shpigelman A et al (2015) FT-IR spectroscopy, a reliable method for routine analysis of the degree of methylesterification of pectin in different fruit- and vegetablebased matrices. Food Chem 176:82-90. https://doi.org/10.1016/j. foodchem.2014.12.033

Mansur HS, Sadahira CM, Souza AN, Mansur AAP (2008) FTIR spectroscopy characterization of poly (vinyl alcohol) hydrogel with different hydrolysis degree and chemically crosslinked with glutaraldehyde. Mater Sci Eng C 28:539-548. https://doi.org/10. 1016/j.msec.2007.10.088

Mishra RK, Majeed ABA, Banthia AK (2011) Development and characterization of pectin/gelatin hydrogel membranes for wound dressing. Int J Plast Technol 15:82-95. https://doi.org/10.1007/ s12588-011-9016-y

Pawar RS, Chaurasiya PK, Rajak H et al (2013) Wound healing activity of Sida cordifolia Linn. in rats. Indian J Pharmacol 45:474-478. https://doi.org/10.4103/0253-7613.117759

Rai N, Bal T, Swain S (2020) In vitro evaluations of biodegradable polyacrylamide grafted moringa bark gum graft copolymer
(MOG-g-PAAM) as biomedical and controlled drug delivery device synthesized by microwave accelerated free radical synthesis. Indian J Pharm Educ Res 54(2):385-396. https://doi.org/10. 5530/ijper.54.2.44

Rezvanian M, Ahmad N, Mohd Amin MCI, Ng SF (2017) Optimization, characterization, and in vitro assessment of alginate-pectin ionic cross-linked hydrogel film for wound dressing applications. Int J Biol Macromol 97:131-140. https://doi.org/10.1016/j.ijbio mac.2016.12.079

Rm V, Nair BR (2018) A study on the antioxidant and antibacterial potential of the mucilage isolated from Hibiscus. J Pharmacogn Phytochem 7:1633-1637

Roy D, Bal T, Swain S (2020) Fabrication and evaluation of pH-sensitive biocompatible microwave irradiated moringa barkgum-carrageenan (MOG-CRG-IPN) interpenetrating isotropic polymeric network for controlled delivery of pharmaceuticals. Sustain Chem Pharm 18:100325. https://doi.org/10.1016/j.scp.2020.100325

Swain S, Bal T (2019) Microwave irradiated Carrageenan-Guar gum micro-porous IPN: a novel material for isotropic tissue scaffolding. Int J Polym Mater Polym Biomater 68:796-804. https://doi. org/10.1080/00914037.2018.1506986

Vashisth P, Pruthi V (2016) Synthesis and characterization of crosslinked gellan/PVA nanofibers for tissue engineering application. Mater Sci Eng C 67:304-312. https://doi.org/10.1016/j. msec.2016.05.049

Publisher's Note Springer Nature remains neutral with regard to jurisdictional claims in published maps and institutional affiliations. 